\title{
Exhaled Nitric Oxide - Circadian Variations in Healthy Subjects
}

\author{
M. Antosova ${ }^{1}$, A. Bencova ${ }^{2}$, A. Psenkova ${ }^{3}$, D. Herle 2 , E. Rozborilova ${ }^{2}$ \\ ${ }^{1}$ Institute of Pharmacology, Jessenius Faculty of Medicine, Comenius University, Martin, Slovakia; ${ }^{2}$ Clinic of Tuberculosis and Respiratory \\ Diseases, Jessenius Faculty of Medicine, Comenius University and MFN, Martin, Slovakia; ${ }^{3}$ Institute of Nursing Jessenius Faculty of \\ Medicine, Comenius University, Martin, Slovakia
}

\begin{abstract}
Objective: Exhaled nitric oxide (eNO) has been suggested as a marker of airway inflammatory diseases. The level of eNO is influenced by many various factor including age, sex, menstrual cycle, exercise, food, drugs, etc. The aim of our study was to investigate a potential influence of circadian variation on eNO level in healthy subjects.

Methods: Measurements were performed in 44 women and 10 men, non-smokers, without respiratory tract infection in last 2 weeks. The eNO was detected at 4hour intervals from 6 a.m. to 10 p.m. using an NIOX analyzer. We followed the ATS/ERS guidelines for eNO measurement and analysis.

Results: Peak of eNO levels were observed at 10 a.m. (11.1 $\pm 7.2 \mathrm{ppb})$, the lowest value was detected at 10 p.m. (10.0 $\pm 5.8 \mathrm{ppb})$. The difference was statistically significant (paired t-test, $\mathrm{P}<0.001$ ).

Conclusions: The daily variations in eNO, with the peak in the morning hours, could be of importance in clinical practice regarding the choice of optimal time for monitoring eNO in patients with respiratory disease.
\end{abstract}

Key words: exhaled nitric oxide, circadian variation

\section{INTRODUCTION}

Nitric oxide (NO) is a messenger molecule involved in many biological functions. It is possible to detect the actual concentration of this molecule in exhaled breath using chemiluminescence. This method was first described in 1991 by Gustafsson et al [1]. Monitoring of exhaled NO (eNO) is an important non-invasive methods of diagnosis and assessment of inflammation in the respiratory tract. The lungs of healthy human subjects produce low, but detectable amounts of NO, which probably reflects the activity of cNOS [2, 3]. eNO is significantly increased during inflammatory diseases in airways, which is probably associated with increased expression of iNOS [4]. High levels of eNO have been detected in patients with bronchial asthma, chronic obstructive pulmonary disease, upper respiratory tract infection, etc. In contrast, decreased level of eNO was observed in subjects with sinusitis, hypoxia, cystic fibrosis, or in primary pulmonary hypertension [5]. eNO air may be affected by a number of factors. Food rich to nitrates, medicines containing L-arginine, ACE inhibitors, and other factors increase eNO $[6,7]$. Reduced level of eNO is observed in smokers or alcohol consumers, patients treated with corticosteroids, prostaglandins, or antituberculotic drugs [8]. Caffeine significantly reduces the level of exhaled NO in healthy subjects [9], but does not influence eNO in patients with asthma [10]. eNO is also reduced by physical activity, decrease of body temperature, or repeat spirometry. One of the as yet unstudied factors that may affect eNO is human biorhythm. Therefore, in the present study, we focused our attention on the possible circadian variations in eNO levels in healthy adults. The aim of the study was to elucidate the influence of the 24-hour human biorhythm on eNO levels.

\section{Material AND Methods}

\section{SUBJECTS}

The study was approved by a local ethics Committee. The study population consisted of healthy volunteers who were enrolled into the study on the basis of the following criteria: age 18-50 yr; non-smoking, no acute respiratory infection in the 3 weeks prior to examination, no symptoms of lower disease (cough, shortness of breath) or upper respiratory tract disease (nasal itching, nasal obstruction and/or discharge), negative history of allergy and/or chronic respiratory disease, and willingness to cooperate. Fifty four subjects (10 men and 44 women, mean age 22 years were recruited for the study. The first eNO measurement was performed at 6 a.m. and then repeated measurements were performed at regular 4-hour intervals (10 a.m., 2, 6 , and 10 p.m.). All subjects were informed about the factors potentially affecting the level of NO in the human body and were recommended to avoid food, drink, smoking, or extreme physical activity an hour prior to examination.

\section{MeAsurement of Exhaled NO}

Exhaled NO was measured using a chemiluminiscence analyzer NIOX (Aerocrinne, Sweden), according to the American Thoracic Society (ATS) and European Respiratory Society (ERS) guidelines [11]. The recommended technique for adult patients involves inspiration of NO-free air via a mouthpiece to total lung ca- 
pacity, followed immediately by $10 \mathrm{~s}$ exhalation against a constant, positive counter pressure of $10-20 \mathrm{~cm}$ $\mathrm{H}_{2} \mathrm{O}$ to ensure an exhalation flow rate of $50 \pm 5 \mathrm{ml} / \mathrm{s}$. The results are expressed as the mean of 3 acceptable measurements of NO concentration in $\mathrm{ppb}$. The counter pressure is controlled by both visible and audible feedback in order to guide the subject in performing a valid exhalation maneuver.

\section{STATISTICAL ANALYSIS}

The mean value of three eNO measurements was calculated for each subject. Data were expressed as means \pm SE. The data were processed by macroscopic chronobiometric analysis. One-way analysis of variance ANOVA was used to compare the differences of eNO among the individual time point measurements. An unpaired student t-test was used to compare the differences depending on gender. All data were processed using Microsoft Excel and statistical software NCSS 2007.

\section{RESULTS}

The results are based on repeated measurements of eNO levels performed in 54 human healthy volunteers. The mean values of eNO measured at fixed time intervals are presented in Fig 1. The highest value of

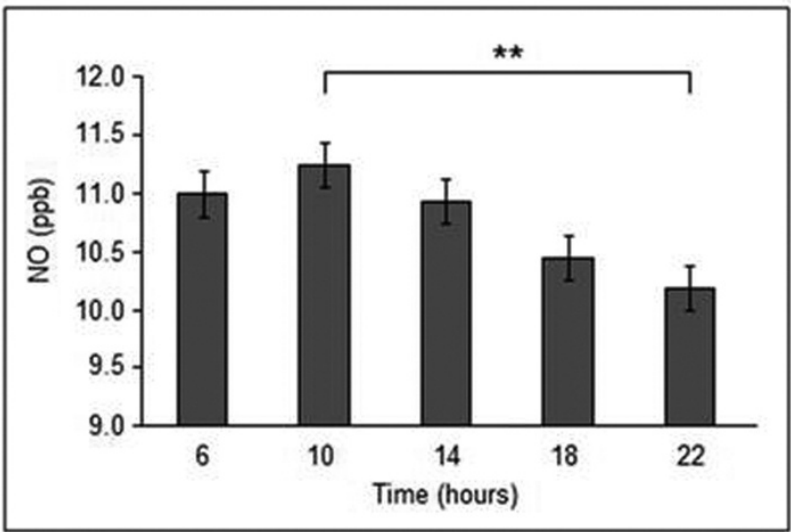

Fig. 1. Exhaled NO mean values.

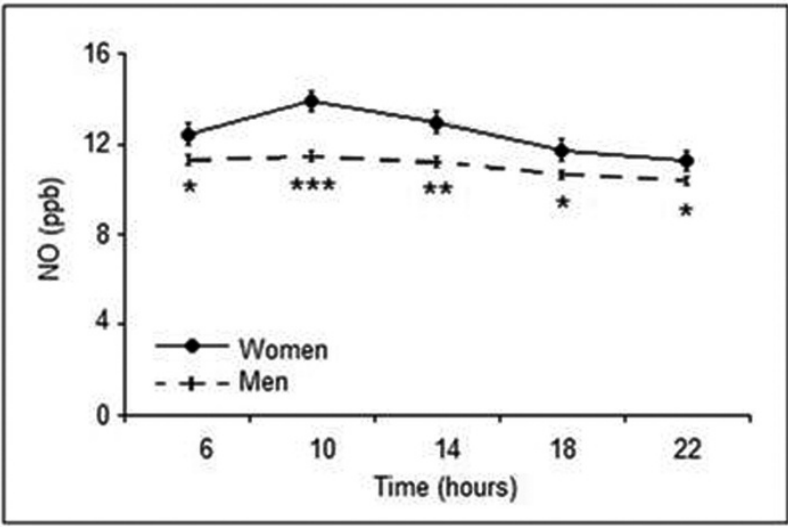

Fig. 2. Exhaled NO mean values in women and men.
eNO was recorded at 10 a.m. (11.1 $\pm 7.2 \mathrm{ppb})$, the lowest value was recorded at 10 p.m. $(10.0 \pm 5.8 \mathrm{ppb})$. The results show a circadian dependence of eNO on time. The difference between 10 a.m. and 10 p.m. was statistically significant (paired t-test, $\mathrm{P}<0.001$ ). The mean value of eNO in women was significantly lower than that in men at all time points $(\mathrm{P}<0.01)$ (Fig. 2)

Table 1. Characteristics of subjects.

\begin{tabular}{lcc}
\hline & Women $(\mathrm{n}=45)$ & Men $(\mathrm{n}=10)$ \\
\hline Age & $21.6 \pm 0.9$ & $23.8 \pm 4.7$ \\
Weight $(\mathrm{kg})$ & $61.0 \pm 9.4$ & $78.7 \pm 15.5$ \\
Height $(\mathrm{cm})$ & $168.3 \pm 5.8$ & $179.9 \pm 4.6$ \\
\hline
\end{tabular}

\section{Discussion}

There is increasing evidence for utilization of exhaled NO in clinical practice, especially for monitoring patients with asthma and allergic rhinitis. For this reason, it is important to analyze all potential and actual factors affecting the level of $\mathrm{NO}$ in exhaled air. As outlined above, the synthesis of $\mathrm{NO}$ is determined by a sufficient availability of the L-arginine substrate and the expression and activity of NO synthase. In the present study, we demonstrate a circadian rhythm in eNO. Top eNO levels were observed at 10 a.m. From this peak, eNO slowly declines to its lowest value detected at 10 p.m. Mattes et al [12] also described a significant circadian rhythm in eNO. In that study, the measurement of eNO was carried out at $3 \mathrm{~h}$ intervals during 24 hours, and there was a decrease in eNO levels at 10 p.m., and then it started increasing after 1 a.m., culminating at 7 a.m. Circadian variation in $\mathrm{NO}$ has also been found in a study on nasal nitric oxide (nNO) concentration [13]. nNO values were low in the morning, reached a plateau during the day, and decreased between 17 and 19 p.m. Georges at al [14] hypothesized that eNO would increase at night. They observed that circadian rhythm in eNO differed greatly between nocturnal and non-nocturnal asthma. A significant decrease in eNO in nocturnal asthma may reflect an important chronobiological defect in endogenous NO production and could play a role in nocturnal exacerbations of asthma. On the other side, there is a report that eNO does not show any significant variations in subjects with nocturnal bronchial asthma [15]. In that study, however, patients with asthma had higher levels of eNO both at night and day; this may reflect more severe diurnal airway inflammation. In the present study, we also observed significant differences in eNO values between women and men. Various studies indicate that the hormone estradiol in females may enhance NO-production [16]. Clarification of the relationship between sex, hormone levels in plasma, and the level of exhaled $\mathrm{NO}$ will be the aim of our next study. Based on the present results we can hypothesize that the circadian variation in eNO is important for diagnosis and monitoring of patients with respiratory diseases. It seems warranted to choose the optimal time for the eNO measurement and to maintain the same time throughout the monitoring process. 
Acknowledgement: Supported by VEGA 1/0055/08, Grant MZ 2007/46-UK-11, Grant UK 423/2008.

Conflicts of interest: The authors declared no conflicts of interest in relation to this article.

\section{REFERENCES}

[1] Gustafsson LE, Leone AM, Person MG, Wiklund NP, Moncada S. Endogenous nitric oxide is present in the exhaled air of rabbits, guinea pigs and humans. Biochem Biophys Res Commun 1991; 181: 852-7.

[2] Hyde RW, Geigel EJ, Olszowska AJ, Krasmeu JA, Forster RE, Utell MJ, Frampton MW. Determination of production of nitric oxide by lower airways of humans: theory. J Appl Physiol 1997; 82: 1290-6.

[3] Nijkamp FP, Folkerts G. Nitric oxide: initiator and modulator. Clin Exp Allergy 1997; 27: 347-50.

[4] Kharitonov SA, Yates D, Robbins RA, Logan-Sinclair R, Shinebourne EA, Barnes PJ. Increased nitric oxide in exhaled air of asthmatic patients. Lancet 1994; 343: 133-35.

[5] Dweik RA. The promise and reality of nitric oxide in the diagnosis and treatment of lung disease. Cleveland Clin J Med 2001; 68(6): 486-90.

[6] Cáp P. The importance of eNO analysis in patients with asthma. Cas Lek Ces 2004; 143: 381-4.

[7] Kharitonov SA, Barnes PJ. Exhaled markers of pulmonary diseases. Am J Respir Crit Care Med 2001; 163: 1693-772.

[8] Yates DH. Role of exhaled nitric oxide in asthma. Immunol Cell Biol 2001; 79: 178-90.

[9] Bruce C, Yates D, Thomas P. Caffeine decreases exhaled nitric oxide. Thorax 2002; 57: 361-63.

[10] Taylor ES, Smith AD, Cowan JO, Herbison GP, Taylor DR. Effect of caffeine ingestion on exhaled nitric oxide in measurements in patients with asthma. Am J Respir Crit Care Med 2004; 169(9): 1019-21.
[11] ATS/ERS recommendations for standardized procedures for the online and offline measurement of exhaled lower respiratory nitric oxide and nasal nitric oxide, 2005. Am J Respir Crit Care Med 2005; 171: 912-30.

[12] Mattes J, Storm van's Gravesande K, Moeller C, Moseler M, Brandis M, Kuehr J. Circadian variation of exhaled nitric oxide and urinary eosinophil protein $\mathrm{X}$ in asthmatic and healthy children. Pediatr Res 2002; 51(2): 190-4.

[13] Dressel H, Bihler A, Jund F, de la Motte D, Nowak D, Jorres RA, Kramer MF. Diurnal variation of nasal nitric oxide levels in healthy subjects. J Investing Allergol Clin Immunol 2008; 18(4): 316-23.

[14] Georges G, Bartelson BB, Martin RJ, Silkoff PE. Circadian variation in exhaled nitric oxide in nocturnal asthma. J Asthma 1999; 36(5): 467-73.

[15] Hacken NHT, van der Vaart H, van der Mark TW, Koeter GH, Postma DS. Exhaled nitric oxide is higher both at day and night in subject with nocturnal asthma. Am J Respir Crit Care Med 1998; 158: 902-7.

[16] Jilma B, Kastner J, Mensik C, Vondrovec B, Hildebrandt J, Krejcy K, Wagner OF, Eichler HG. Sex differences in concentrations of exhaled nitric oxide and plasma nitrate. Life Sciences 1996; 58(6): 469-76.

Corresponding Author:

Martina Antosova, Mgr., PhD

Institut of Pharmacology

Jessenius Faculty of Medicine

Sklabinska 26

Martin 03601, Slovakia

Phone: +421908 267503

Antosova@jfmed.uniba.sk 